\title{
Thermal Management of Electrified Propulsion System for Low-Carbon Vehicles
}

\author{
Bo Li ${ }^{1}$. Huang Kuo ${ }^{1} \cdot$ Xuehui Wang ${ }^{1} \cdot$ Yiyi Chen ${ }^{2} \cdot$ Yangang Wang ${ }^{2} \cdot$ David Gerada $^{1} \cdot$ Sean Worall ${ }^{3} \cdot$ lan Stone ${ }^{3}$. \\ Yuying Yan ${ }^{1}$
}

Received: 30 March 2020 / Accepted: 29 October 2020 / Published online: 2 December 2020

(c) The Author(s) 2020

\begin{abstract}
An overview of current thermal challenges in transport electrification is introduced in order to underpin the research developments and trends of recent thermal management techniques. Currently, explorations of intelligent thermal management and control strategies prevail among car manufacturers in the context of climate change and global warming impacts. Therefore, major cutting-edge systematic approaches in electrified powertrain are summarized in the first place. In particular, the important role of heating, ventilation and air-condition system (HVAC) is emphasised. The trends in developing efficient HVAC system for future electrified powertrain are analysed. Then electric machine efficiency is under spotlight which could be improved by introducing new thermal management techniques and strengthening the efforts of driveline integrations. The demanded integration efforts are expected to provide better value per volume, or more power output/torque per unit with smaller form factor. Driven by demands, major thermal issues of high-power density machines are raised including the comprehensive understanding of thermal path, and multiphysics challenges are addressed whilst embedding power electronic semiconductors, non-isotropic electromagnetic materials and thermal insulation materials. Last but not least, the present review has listed several typical cooling techniques such as liquid cooling jacket, impingement/spray cooling and immersion cooling that could be applied to facilitate the development of integrated electric machine, and a mechanic-electric-thermal holistic approach is suggested at early design phase. Conclusively, a brief summary of the emerging new cooling techniques is presented and the keys to a successful integration are concluded.
\end{abstract}

Keywords Thermal management · Electrified powertrain · Efficient cooling and heating · Electric machine and control · High power electronics

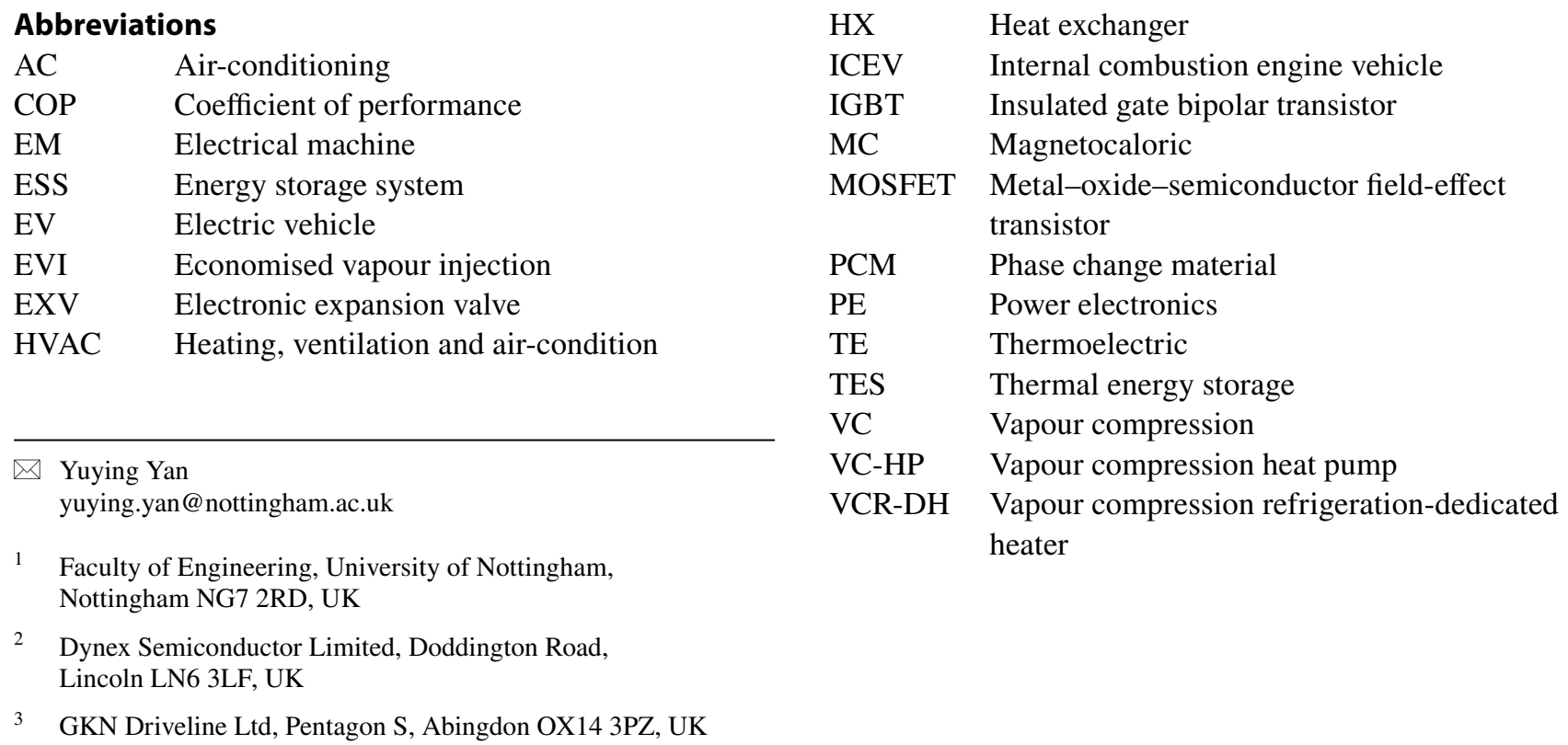




\section{Introduction}

The phase-out of diesel and petrol cars proposed by quite a few countries has actually given an imperative impetus for achieving electrified propulsion systems in automotive sectors. Last decades saw a great momentum of successful research and development on new electrified vehicular powertrains, such as hybrid electric vehicles (HEVs) and full battery electric vehicles (BEVs). Unlike the conventional internal combustion engines (ICEs), the newly developed electric powertrains mostly have much higher energy efficiency which means more effective work to wheels under electrified driveline. Ultimately, it is expected that both automotive industries and consumers around the world can benefit from the carbon dioxide reducing endeavours. To achieve this, the effort to improve the powertrain system is always continuing, and higher performance and reliable components and subsystems are emerging everyday to the end-users in the market. Thermal management improvement is one of the research focuses that could potentially provide more temperature regulating solutions to achieve these targets. Indeed, it may not be simply achieved by changing or developing a single material or component; new thermal management systems and control strategies will emerge along with new HEV/ EV architectures with higher voltage products. Therefore, a comprehensive review is introduced on current thermal management technologies and a helicopter view on the trends in this area in future. It is noteworthy that the thermal management for battery is out of scope here due to already existed publications. Instead, electric machine, power modules and powertrain systems are our selected topics in respective sections.

\section{Thermal Management Systems in Powertrain}

The significance of vehicle thermal management system is to improve the automotive thermal efficiency, as well as to achieve passenger comfort and long-lasting component reliability. There are increasing researchers exploring advanced approaches to vehicle thermal management to increase fuel economy while maintaining passenger comfort. The effectiveness of vehicle thermal management systems can be evaluated by the thermal load reduction for automotive powertrains and the thermal comfort improvement in cabins. In the same time, an efficient vehicle thermal management system can boost the automotive thermal efficiency which leads to higher fuel economy of internal combustion engine vehicles (ICEVs) or miles per charge of electric vehicles (EVs); therefore, an optimised vehicle thermal management system is crucial for both ICEVs and EVs [1]. The difference between the thermal management solutions for ICEVs and EVs is also obvious, which exists in the energy source, powertrain and HVAC system [2, $3]$. The energy of propulsion in ICEV s comes from the combustion of fossil fuel in ICE. With regard to EVs, this energy is provided by batteries instead of engines [4]. The elimination of engine waste heat, combined with advanced thermal management requirements in electrified powertrain, leads to new challenges in thermal load reduction and cabin comfort in EVs. According to the difference in operating temperature, EVs have two separate loops for cooling batteries, electric motors and power electronics [5], as shown in Fig. 1. The battery thermal management system has seen decent development during the last few years. Many contributions have been made in research of controlling battery-operating temperature and improving battery temperature consistency by global research institutions and car manufactures [6-8]. There are plentiful studies reviewing the recent development of battery thermal management for EVs $[9,10]$; therefore, the present work will mainly focus on the thermal management of electrified powertrain and HVAC system for EVs.

\subsection{Thermal Management in Electrified Powertrain}

The powertrains for ICEVs and EVs are completely different, thus resulting in requirement of different thermal management systems. With regard to ICEVs, ICE is the core component for generating work and the focus of thermal management. A typical ICE produces enough excess mechanical power to drive water pump, compressor and other heat dissipating components to control the temperature of engine and cabin. Different from ICEVs, batteries are the main power source of EVs; therefore, the thermal management of batteries is more important in EVs [11, 12]. Moreover, although the electric power components can achieve higher power efficiency with relatively lower heat generating rate, the high temperature sensitivity and low operating

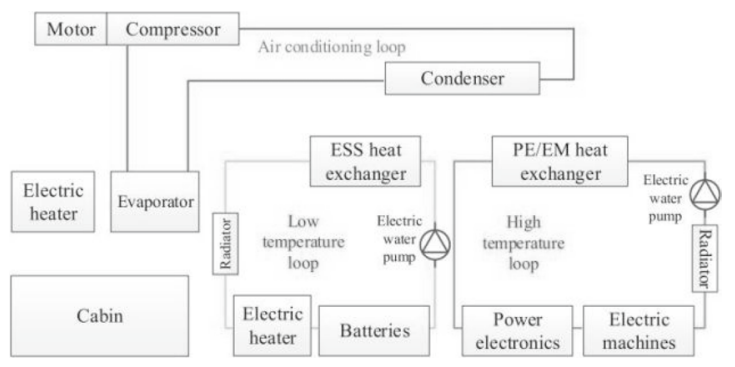

Fig. 1 Schematic of a thermal management system for electric vehicle [5] 
temperature range of these components require that the thermal management system must have quick real-time response to the vehicle driving condition $[13,14]$. Motor, power modules and transmission are three major components that need to be cooled down by the thermal management system in electrified powertrain.

With the development of EVs, the modern electrified powertrain is highly integrated. The integration of motor, power module and transmission takes the advantages of downsizing layout space, reducing the total weight of powertrain and flexibility for different platforms [15]. The cooling circuit of thermal management system will also be simplified as a result of highly integrated electrified powertrain $[16$, 17]. Normally, there is a low-temperature water circuit for cooling the silicon steel sheets in the stator of the motor and power module and a high-temperature oil circuit for cooling copper winding in the motor and transmission box. Because of the integration, the water circuit and oil circuit can be combined together; the heat will be exchanged between these two circuits to achieve the operating temperature for each component, as shown in Fig. 2.

Therefore, the thermal management for an electrified powertrain should consider the cooling for each component as well as the distribution of cooling circuits, in order to achieve the best thermal performance with the lowest pumping power and maintain the temperature of each component

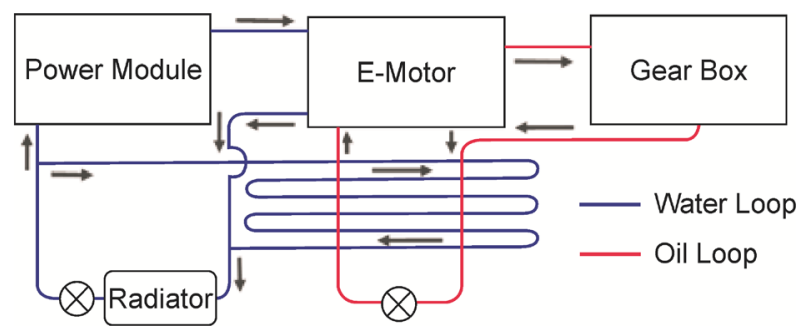

Fig. 2 Distribution of cooling circuits in integrated electrified powertrain

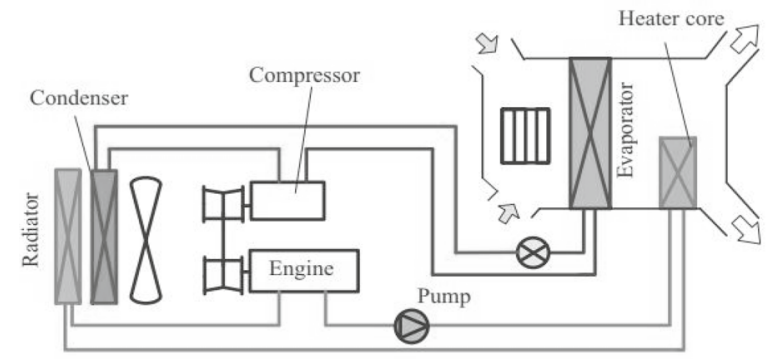

(a) at its optimal value. The detailed review on the thermal management technologies for motor and power modules will be presented in the following section.

\subsection{HVAC System in Electric Vehicles}

The HVAC systems in cars provide heating, ventilation and air-conditioning (AC) in the cabin of all the vehicles. It is necessary to control the interior thermal environment of the vehicle and ensure safety in visibility. The difference between the HVAC systems in ICEVs and EVs can be well summarised as follows. Firstly, the difference in driving power for compressor needs to be noted [18]. The compressor in ICEVs is a belt-driven component mechanically coupled to the engine crank shaft; the performance is directly related to the vehicle speed; while in EVs, an electricity-driven compressor is utilised and thus the speed of compressor can be adjusted independently to meet the cooling and heating loads. However, the recharge mileage of an EV is reduced drastically when the AC system is operating. Secondly, the waste heat from combustion in ICEVs can be reused for warming up the air in the cabin without further consumption of fossil fuel [19]; whereas, in the EVs, different heating schemes and sources are necessary in order to heat vehicle cabin as the waste heat gained from the motors and battery is normally far less than the demand of heating cabin. Therefore, EVs are faced with a particular challenge to the development of more efficient AC systems. The configuration of AC system in ICEVs and EVs is shown in Fig. 3.

There are mainly two solutions for AC system in EVs, namely AC system based on vapour compression (VC) cycle or AC system without VC cycle [20]. The VC cycle is still dominant in the $\mathrm{AC}$ systems for EVs. There are two different methods for heating the air in cabin. One is the vapour compression refrigeration-dedicated heater (VCRDH) system, which uses electricity or fuel-operated heater

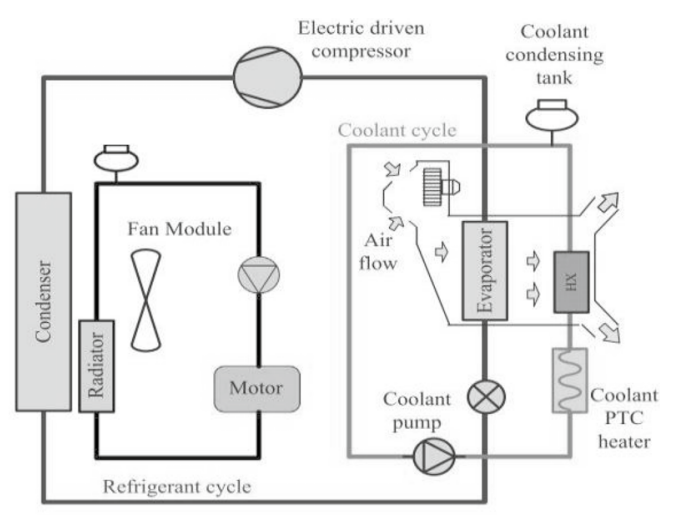

(b)

Fig. 3 Difference between the configuration of AC system in ICVs (a) and EVs (b) [18] 
to warm cabin air; the other is the vapour compression heat pump (VC-HP) system, which achieves the heating by adopting a compressor controlled by the inverter and a four-way valve to reverse the direction of refrigerant flow. The basic structure of VCR-DH system and VC-HP system is shown in Fig. 4.

The VCR-DH system is advantageous for the EVs owing to its reliability and simplicity, but this solution suffers the defect of drastic recharge mileage reductions caused by large electricity consumption of heating, especially in cold districts [21]. Normally, the driving range decreases by about $15 \%$ and $45 \%$ when cooling system and heater are operated, respectively [22]. There are plenty of efforts having been made to improve the thermal efficiency of the VCR-DH system. In Toyota Prius, a two-phase ejector was employed to improve the system efficiency [23]. The ejector was integrated into the evaporator to reduce the volume of the device. The ejector reduces compressor power consumption by $11 \%, 18 \%$ and $24 \%$ at different temperature ranges for the Prius HEVs. The different coolant operating model could also play an important role in improving thermal efficiency. The coolant flow can be coordinated by a valve to link or unlink with the battery cooling system, in order to get a shorter warm-up phase [24]. High-voltage layer heater is another technology that can reduce the energy consumption by about $18 \%$ in the warm-up phase than other comparable technologies [25]. Moreover, this innovative high-voltage layer heater can achieve the power density of $3.2 \mathrm{~W} / \mathrm{cm}^{3}$, which is almost twice of that achieved by the positive temperature coefficient (PTC) heater, with less weight added to the whole vehicle [26]. The improvement in sintering process or coating to enhance heat transfer between surfaces is another optimisation mechanism to the energy consumption of the EV's heating system. Shin et al. [27] and Bauml et al. [28] carried out a series of studies on sintering and coating process, reducing energy consumption of the VCR-DH system by $70 \%$ and 50\%, respectively.

The VC-HP system is promising owing to the prospects of energy efficiency and compact system; however, there are many obstacles that prevent this system from practical application, such as decrements of heating capacity in cold weather and defrosting of exterior heat exchanger. The basic VC-HP AC system of EV is similar to the residential heat pump AC system, and according to the research from Clodic et al. [29] the driving range of EVs can be decreased by $10 \%$ in winter and by $15 \%$ in summer with the employment of the reversible VC-HP system. Obviously, the heat pump system is a practical and promising solution to the $\mathrm{AC}$ systems in EVs [30] and the aim of the VC-HP system in EVs is suggested generally to be focused on demisting and dehumidifying [31]. The improvement on thermal efficiency of VC-HP systems is divided into different routes. Several technologies, such as hybrid systems with an electric heater, economised vapour injection (EVI) and waste heat recovery, have been utilised to improve the heating performance at low ambient temperatures [32]. Kim et al. [33] presented a combined system consisting of a heat pump and a PTC heater as a heating unit in EVs. Experimental results showed that the heating capacity was increased by $59 \%$ for the combined system and the coefficient of performance (COP) was also increased significantly in heat pump system. Li et al. $[34,35]$ designed an air-source heat pump based on a scroll compressor operating with EVI cycle for EVs and carried out a series of simulation and experimental studies. Results indicated that the system COP is about 1.5 and the heating capacity of the system increases more than $20 \%$ when the ambient air temperature is $-20^{\circ} \mathrm{C}$. In 2016, Qian et al. [36] conducted an experiment to verify the feasibility of a dualsource VC-HP system using both ambient air and waste heat

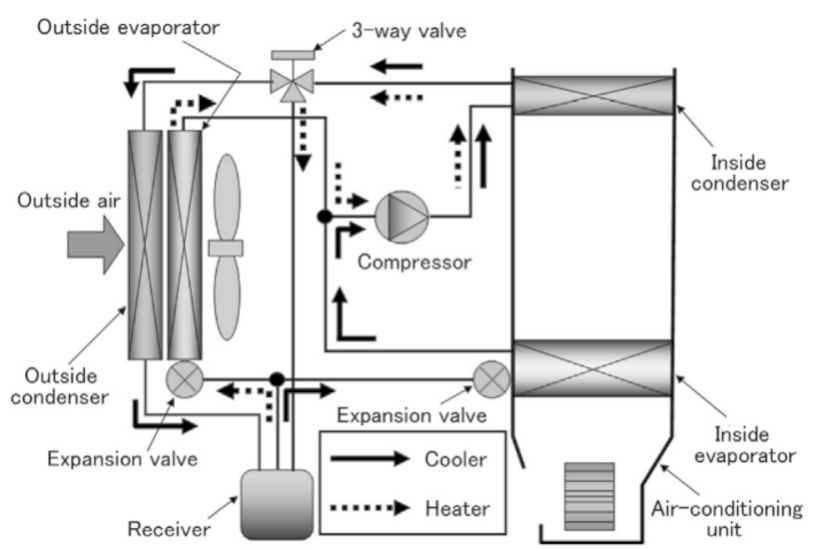

(b)

Fig. 4 Structure schematic for AC systems based on VC cycle: a VCR-DH system and b VC-HP system [20] 
of the motor as the low-temperature heat sources in EVs. Results showed that the heating capacity and system COP were increased by $24.16 \%$ and $10.81 \%$, respectively, compared with the conventional air-source system.

In addition to the $\mathrm{VC}$ cycle-based $\mathrm{AC}$ system, there are alternative solutions of AC systems, such as thermal energy storage (TES) AC system, magnetocaloric (MC)-based AC system and thermoelectric (TE)-based AC system. According to the thermal storage materials, the TES AC systems can be divided into sensible heat storage system and latent heat storage system. The material with a high specific heat is preferred for high storage energy density. The capability of storing sensible heat is restricted by the freezing point and boiling point of the material. Latent heat energy is absorbed or released by a phase change material (PCM) during the process of melting or solidification. Shahidinejad [37] introduced passive TES system using PCM to maintain the cabin temperature for driving comfort in 2012. Li and Jiang [38] proposed a

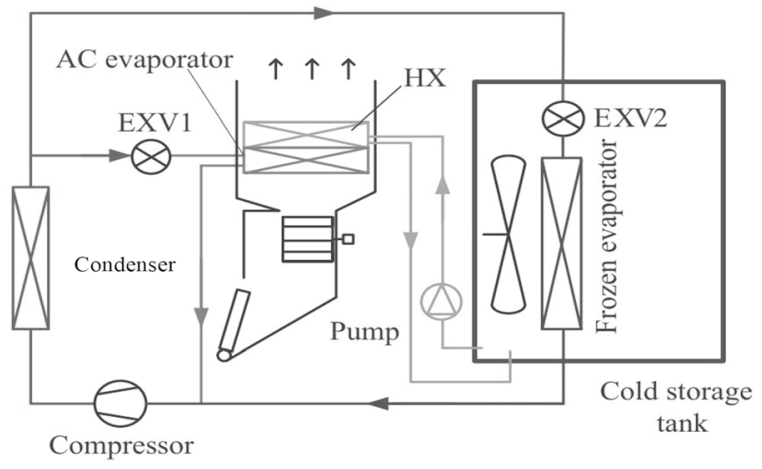

Fig. 5 Schematic diagram of a AC system with TES [38]

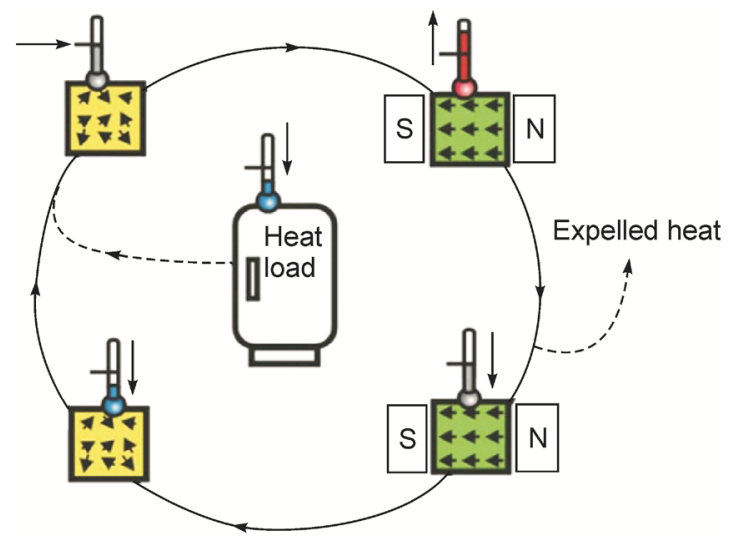

(a)
TES system for EVs in 2017 as shown in Fig. 5. Compared with the traditional AC system, a cold regenerator circuit was added to reserve the energy from the electric grid through the control panel, when the EV is plugged in. It was claimed that the TES system can save the total cost and increase the driving range for the EV.

The MC-based AC system is based on the magnetocaloric effect when it is applied to different metallic materials and new alloys-named magnetocaloric materials. When the material is subjected into a strong magnetic field, the heat will be generated as a consequence of the intrinsic effect of spin orientation. Figure 6 shows the schematic diagram and a prototype of a magnetic refrigeration cycle with two phases. Gómez et al. [39] firstly reviewed the application of MC-based AC system near room temperature in the past decades. The new EV climate control system will be composed of the two phases with both cooling and heating under near room-temperature [40, 41].

The TE-based AC system is based on the Peltier effect when an electric current pass through a pair of semiconductors and heat is evolved at one junction and absorbed at the other junction. In TE-based AC system, heating or cooling can be easily switched by changing the electricity current direction. Alaoui and Salameh [42] developed a novel thermal management system for EVs, which consists of thermoelectric modules using Peltier effect to heating and cooling the cabin temperature. It is experimentally proved that TE-based AC system is applicable, but its COP is relatively low, which were 0.65 and 0.23 in heating and cooling modes, respectively.

The advantages and disadvantages of the AC systems mentioned are listed in Table 1.

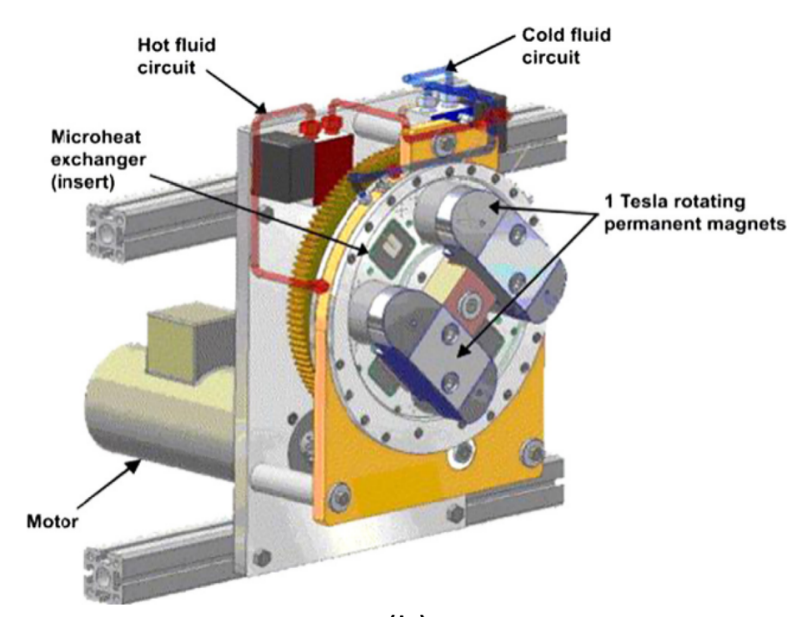

(b)

Fig. 6 Schematic diagram (a) magnetic refrigeration cycle and (b) magnetocaloric heat pump prototype [39, 41] 
Table 1 Performance comparisons of potential AC systems for EVs

\begin{tabular}{|c|c|c|}
\hline AC system & Advantages & Disadvantages \\
\hline \multicolumn{3}{|c|}{ Vapour compression refrigeration cycle based } \\
\hline VCR-DH system & Simple; reliable; low noise & $\begin{array}{l}\text { Low heating COP; reduce driving range; alternative } \\
\text { refrigerant issue }\end{array}$ \\
\hline VC-HP system & $\begin{array}{l}\text { High capacity density; compact system; relatively } \\
\text { high COP }\end{array}$ & $\begin{array}{l}\text { Control strategy; low COP at cold condition; alternative } \\
\text { refrigerant issue }\end{array}$ \\
\hline \multicolumn{3}{|c|}{ New heat pumping cycle based } \\
\hline TES AC systems & Energy efficient; high performance & Cumbersome; lower energy density \\
\hline MC-based AC system & $\begin{array}{l}\text { Quiet; compact system; no alternative refrigerant } \\
\text { issue }\end{array}$ & $\begin{array}{l}\text { Large magnetic field; poor COP; heat exchangers } \\
\text { required; driving range losses }\end{array}$ \\
\hline TE-based AC system & $\begin{array}{l}\text { Quiet; compact system; easy mode switch; no work- } \\
\text { ing fluid; }\end{array}$ & Less capacity density; lower COP; driving range losses \\
\hline
\end{tabular}

\section{Thermal Management of Electric Vehicles}

\subsection{Electric Motor in Electrified Powertrain}

While the battery performance limits the driving range of an electric vehicle, the motor used to drive the wheels determines the speed and acceleration performance. The latest motor types developed by leading car manufacturers is presented in Table 2, which are mainly categorised into permanent magnet synchronous and induction motors [43]. Permanent magnet is widely used in the rotor of the permanent magnet synchronous motor for improving overall efficiency, which could contribute to less heat generation in high-speed application. It can maintain full torque and high efficiency even at very low speed. From this point of view, it is a promising type of motor which is also suitable for compact propulsion system such as in-wheel or hub motor applications [44]. The magnetic losses generally increase with the size of the motor, along with increasing rare metals used in the magnet. Regarding alternating current induction motor, the technology is relatively mature and independent from critical raw materials such as rare earth and critical metals. The operating mechanism makes it capable to provide high power at high speeds, which is important to achieve higher acceleration performance.

Table 2 Performance and classification comparison of latest motor developments

\begin{tabular}{|c|c|c|c|c|}
\hline Electric vehicle & Manufacturer & Motor power & Motor type & Model year \\
\hline e-Golf SE & Volkswagen & $100 \mathrm{~kW}$ & Permanent magnet synchronous & 2020 \\
\hline i3s edition RoadStyle & BMW & $135 \mathrm{~kW}$ (rear) & Alternating current synchronous & 2020 \\
\hline e-tron Sportback 55 & Audi & 140 kW (rear); 125 kW (front) & $\begin{array}{l}\text { Alternating current induction; } \\
\text { Alternating current induction }\end{array}$ & 2020 \\
\hline Bolt EV & Chevrolet & $150 \mathrm{~kW}$ (front) & Permanent magnet synchronous & 2020 \\
\hline Twingo Z.E.Zen & Renault & $60 \mathrm{~kW}$ (front) & Permanent magnet synchronous & 2020 \\
\hline Model X & Tesla & 375 kW (rear); 193 kW (front) & Alternating current induction; switched reluctance & 2020 \\
\hline Model S & Tesla & 375 kW (rear); 193 kW( front) & Alternating current induction; switched reluctance & 2020 \\
\hline Model 3 & Tesla & $147 \mathrm{~kW}$ (front); $211 \mathrm{~kW}$ (rear) & Alternating current induction; switched reluctance & 2020 \\
\hline MG ZS EV & MG & $105 \mathrm{~kW}$ (front) & Permanent magnet synchronous & 2020 \\
\hline EQC 400 & Mercedes-Benz & Total $300 \mathrm{~kW}$ & Alternating current induction & 2020 \\
\hline e-Niro 4 & KIA & $150 \mathrm{~kW}$ (front) & Permanent magnet synchronous & 2020 \\
\hline IONIQ Electric & Hyundai & $101 \mathrm{~kW}$ (front) & Permanent magnet synchronous & 2020 \\
\hline CITIGOe iV & SKODA & $61 \mathrm{~kW}$ (front) & Permanent magnet synchronous & 2020 \\
\hline Corsa-e & Opel & $100 \mathrm{~kW}$ (front) & Alternating current synchronous & 2020 \\
\hline Taycan $4 \mathrm{~S}$ & Porsche & $160 \mathrm{~kW}$ (front) & Permanent magnet synchronous & 2020 \\
\hline Leaf SL Plus & Nissan & $160 \mathrm{~kW}$ (front) & Alternating current synchronous & 2019 \\
\hline i-pace & Jaguar & $147 \mathrm{~kW}$ (rear); $147 \mathrm{~kW}$ (front) & Permanent magnet synchronous & 2019 \\
\hline $500 \mathrm{e}$ & FIAT & $83 \mathrm{~kW}$ (front) & Permanent magnet synchronous & 2019 \\
\hline
\end{tabular}


It is not restrained by the proportionate losses with the size of the motor. However, the less flexibility to control the rotation speed and frequency could impose a complex design of controller and inverters $[45,46]$. It is an obvious disadvantage considering that the EV typically operates in a wide range of speed.

With determining the specific type of motor being an interesting yet thought-provoking choice for car manufacturers, the limitation of raw material source and long-term market strategies are the key factors in addition to performance requirements from consumer ends. A comprehensive and sustainable choice will be characterised by proper balance between the economic impacts and performance considerations.

\subsection{The Thermal Management of Electric Motors in Electric Vehicles}

Regardless of motors used in the coming electric cars, the higher expectation of the EVs needs more powerful electric motors that are able to deliver higher power density, more torque and higher speed and be more compact in size. Those inevitably lead to more parasitic heat loss generation from the electric motor and impose an increasing challenge for thermal management systems [47]. Generally, an electric motor is a very complex thermal system, with different materials (copper, resin, steel, magnet, etc.) bringing different temperature limitations $[48,49]$. The heat generated in the motor can be identified by Joule losses in winding, mechanical losses in bearings and shaft, iron losses (including hysteretic losses, eddy losses and excess losses) in laminations, and the Joule losses contribute to most of the parasitic heat losses [50]. Such parasitic heat losses must be dissipated efficiently into changing and transient environment, otherwise unregulated temperature increase will cause the demagnetisation of magnetic or deterioration of the motor efficiency, shorter lifespan or even burnout of the motor windings. In this section, latest thermal management technologies for induction motor and permanent magnet motor are comprehensively reviewed and discussed.

The study on potential methodologies of thermal management technologies can be categorised into experimental testing and theoretical modelling. Due to the high complexities and uncertainties of experimental testing, more theoretical modelling studies are available. The notable modelling methods cover the lumped parameter thermal nodes model and finite element method. In lumped parameter methods, the motor sections divided are lumped into several thermal modes and can be a 2D or 3D model, which could result in less accuracy of hotspots prediction and lack of temperature gradient in each thermal node. On the other hand, the finite element method could help simulate the complete motor thermally and provide a more detailed temperature contour of each component within the motor, but the analysis usually requires longer computing time and hardware resources.

\subsubsection{The Thermal Management of Alternating Current Induction Motor}

In low-power-density motor applications, the amount of heat losses is not critical so that traditional air cooling could be adequate. Air cooling including natural and forced convection cooling is capable of keeping the temperature of key components within the safety temperature range. Li et al. [51] studied a fully enclosed air-cooled induction motor used in a small EV. A lumped parameter method was used to propose a steady-state thermal network, and the model is shown in Fig. 7. The results indicated that the temperature of the rotor bar was the highest, followed by the end winding and slot winding in the stator. The influence of axial air cooling path on the rotor was also investigated in this work. In this new cooling topology, the temperature of rotor significantly decreased and the highest temperature point was in the end winding. Ahmed et al. [52] proposed another lumped parameter method to study the transient temperature response for fully enclosed air-cooled induction motor. The simulation coincided well with the experimental results.

Research using the finite element methods to comprehensively study the temperature field of the motor were also reported. Moon et al. [53] numerically investigated the thermal flow of an air-cooled induction motor by finite element method. The geometric parameters of the fins, such as the height, thickness and pitch of the frame, were studied. It was concluded that the height of fins has no apparent attribution to the heat transfer, the pitch of fin was very sensitive to the rise of winding temperature, and it was suggested that the dense finned frame design was a desirable one. Kim et al. [54] reported a 3D computational electromagnetic coupled model to analyse the effect of auxiliary air-gap fans to cool

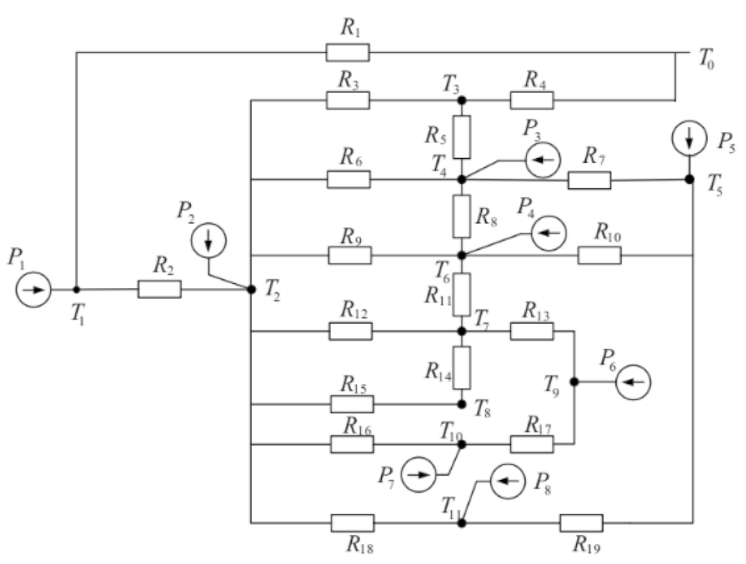

Fig. 7 The lumped parameter model for the induction motor [51] 

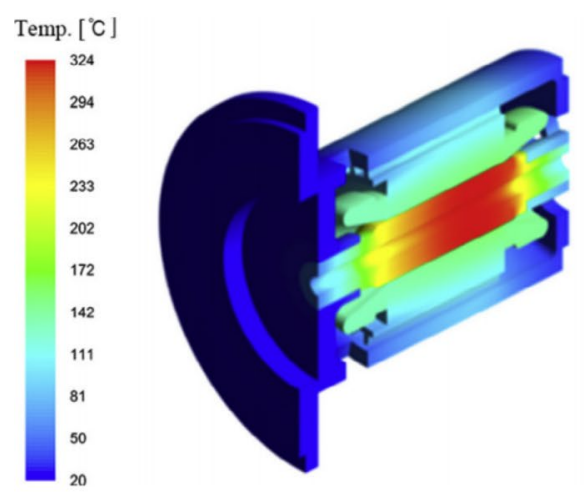

(a)
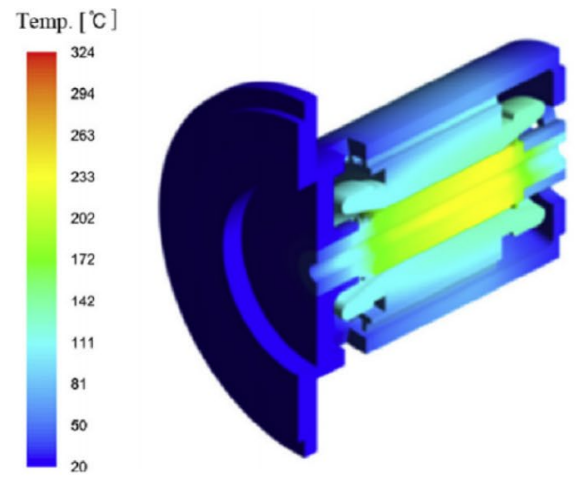

(b)

Fig. 8 The temperature distribution of motor [54] a without air-gap fan; $\mathbf{b}$ with air-gap fan

a large-capacity, high-speed induction motor. As shown in Fig. 8, with the forced convection flow by air-gap fans, the stagnant air at both ends of air gap could be activated and enhance the air flow in the enclosure. The heat transfer coefficients at the winding surface and air gap were improved by $31 \%$ and $90 \%$, respectively.

When it comes to high-performance induction motors, the current air cooling method is inadequate to dissipate the heat from hotspots through convection channels. In these cases, the liquid cooling such as water cooling, water/glycol cooling and oil cooling is recommended. Undoubtedly, the structure of the flow channel has a great impact on the cooling performance.

Song et al. [55] developed a 3D finite element model to simulate the temperature distribution of an induced motor cooled by a water jacket in steady and transient operating conditions.

The heat losses include the iron loss of stator yoke and teeth and copper losses of the stator winding and rotor winding which are quantified by electromagnetic analysis. The steady analysis indicated that the highest temperature and lowest temperature of the motor appeared at the bottom of the rotor slot and the housing, respectively. When it came to transient conditions, the end winding temperature was lower than the centre winding at the beginning 3-5 min. After that, the temperature of the end winding exceeded the centre wingding gradually.

Ranjan et al. [56] presented a parametric finite element thermal modelling for a high-power-density induction motor and also tested the jacket cooling with water/glycol solution as the coolant. The safety temperature was set to $130{ }^{\circ} \mathrm{C}$ as the target motor used some additives. It was found that the achievable current density of winding was $14.6 \mathrm{~A} / \mathrm{mm}^{2}$ and $17.8 \mathrm{~A} / \mathrm{mm}^{2}$ when the inlet temperatures of coolant were $65^{\circ} \mathrm{C}$ and $35^{\circ} \mathrm{C}$, respectively. The experimental investigation was also conducted to in-situ test on the performance of the liquid cooling method. Herbst et al. [57] designed a cooling loop with $50 \% / 50 \%$ water-glycol for the thermal

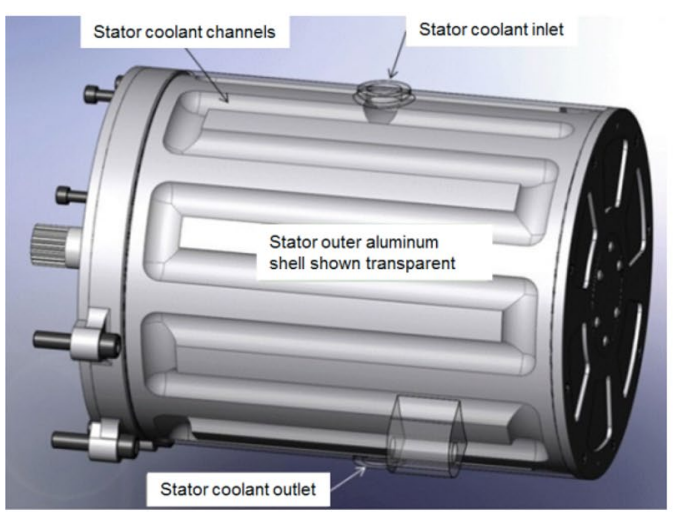

(a)

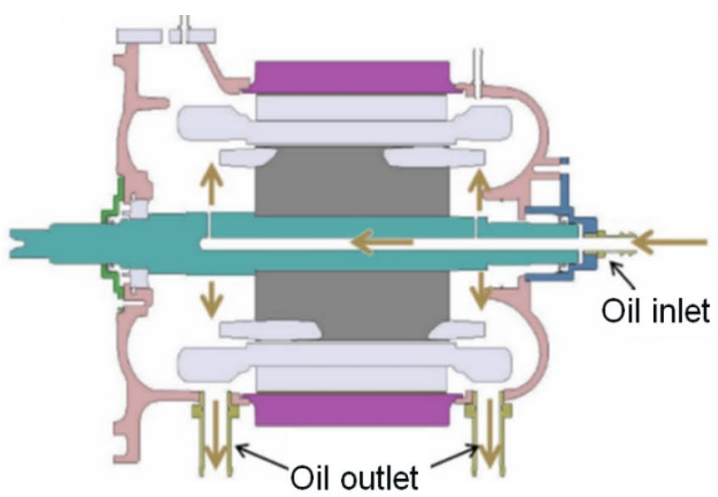

(b)

Fig. 9 Liquid cooling of induction motor a water jacket cooling [57] and b oil cooling [58] 
management of a $100 \mathrm{~kW}$ level induction motors. As shown in Fig. 9a, the fluid split into two, followed separate serpentine axial passages and joined again at the outlet. When the capacity and the inlet temperature of the cooling fluid were $50 \mathrm{~kW}$ and $65^{\circ} \mathrm{C}$, the maximum temperature of the stator predicted was $121.5^{\circ} \mathrm{C}$, which was well below the temperature limit. Assaad et al. [58] proposed an oil-cooled induction motor, whose shaft was hollow functioning as the oil passage and with small holes on its surface. Through these small holes, the oil were projected to the stator end winding and bearings as shown in Fig. 9b. The experimental results indicated that the continuous power of the motor with the oil cooling almost doubled at flow rate $3 \mathrm{~L} / \mathrm{min}$ and rotation speed $5000 \mathrm{rpm}$, respectively. It was also suggested that the selection of oil play an important role in determining the losses.

Generally, there are natural convection cooling, forced convection cooling, water jacket cooling and oil jet cooling technologies developed for the thermal management of alternating current induction motor. They are mainly used to cool the stator winding. However, with the increase in the motor capacity, the corresponding heat loss from rotor should be completely investigated. As the rotor speed tends to increase for the high-capacity induction motor, the cooling of the rotor is not always straightforward by means of conventional cooling techniques, but it will help to achieve more powerful induction motors.

\subsubsection{The Thermal Management of Permanent Magnet Motor}

As aforementioned, the current thermal management technologies mainly aim to tackle heat from stator winding rather than the rotor. Therefore, the cooling technologies used in the induction motor can also be deployed for the permanent magnet motor without much modification. The cooling of the permanent magnet motor also varies with the heat flux of the motor [59].

In permanent magnet motor applications, liquid cooling prevails due to their excellent heat dissipation ability. Lee et al. [60] developed an optimum flow path to cool both the rotor and stator for a permanent magnet motor, and the structure is shown in Fig. 10. The results indicated that the new cooling method effectively decreased the temperature of the motor. The temperature of the winding decreased by about $50 \%$ and $38 \%$ compared with cooling by air and water jacket only, respectively. Rocca et al. [61] presented research on thermal management of high-speed permanent magnet motor with oil cooling. A banding sleeve was used to avoid overly big windage in the air gap. Both the lumped parameter and CFD model were used to analyse the temperature field in the motor. It was found that the cooling strategy

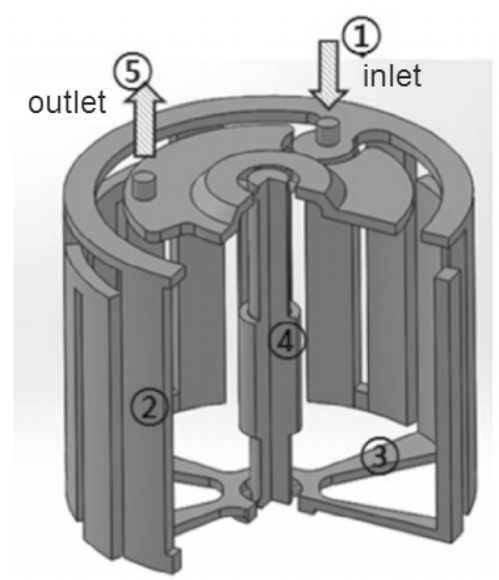

Fig. 10 The cooling structure of oil loop [60]

performed well and the predicted results showed good agreement with experimental data.

To increase the heat dissipation ability of the cooling methods, some hybrid cooling methods were proposed. $\mathrm{Li}$ et al. [62] tested the cooling performance of both water jacket and oil jet cooling. The oil was ejected to the end winding through the nozzles embedded into the end cover, and the structure is shown in Fig. 10. The experimental results indicated a noticeable decrease in the motor temperature, especially for the end winding where the temperature dropped by $20 \%$. Furthermore, with the hybrid cooling, the temperature response was quicker than one only with water jacket cooling. Polikarpova et al. [63] proposed a hybrid cooling method for an axial flux permanent magnet motor. The hybrid cooling method consisted of water jacket cooling in the frame, copper bars in the teeth and potting material in the end winding. It was found that the hybrid system outperformed the water jacket only, and the temperature of the stator winding dropped by $25-35^{\circ} \mathrm{C}$.

In Fig. 11, apart from that, some potential cooling or thermal management technologies were also discussed and provided valuable references for the future commercial applications [64]. Wang et al. [65] introduced the evaporative cooling concept to the thermal management of permanent magnet motor combined with existing water jacket cooling. The cooling mechanism of the motor was discussed, but there were no results revealed. Zhang et al. [66] experimentally studied the temperature profile of permanent magnet motors with phase change material in both continuous and intermitted operation conditions. It was found that the latent heat of the material prolonged the heat durability of the motor by up to $50 \%$. In the intermitted operation condition, the temperature profile was flatter and the peak temperature declined in given conditions. In another similar research, Wang et al. [67] claimed the using of phase change material operated well in extending the safety time duration. 


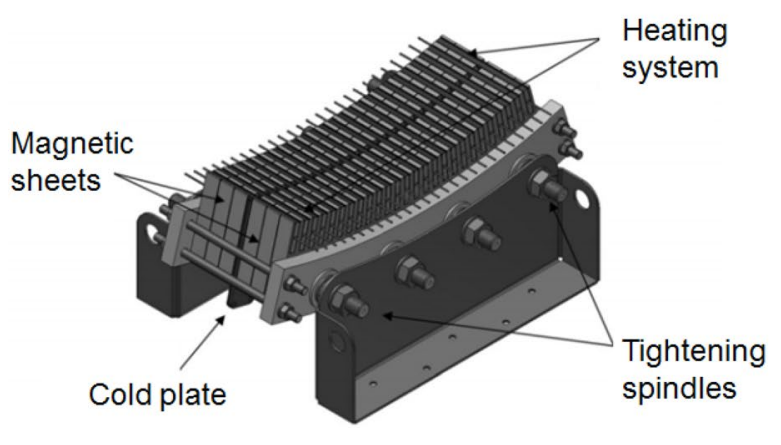

(a)

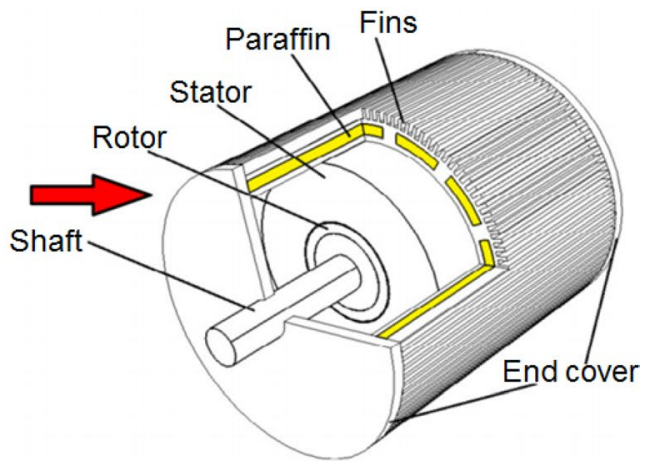

(b)

Fig. 11 Potential thermal management technology a cold plate [64] and $\mathbf{b}$ application of phase change material [65]

There are air cooling, jacket cooling with oil, water, water/glycol, spray cooling and PCMs used for the motors. Generally, air cooling is a economical choice for the motors with low heat density. The liquid cooling has the ability to address higher heat density. For motors with even higher heat density, the hybrid cooling may be needed. It should be noted that thermal management technologies for different motors are similar as their structures are similar. Therefore, the technologies used for other motors can also be used for the alternating current induction machine and permanent magnet motors. Which technology should be used is dependent on the balance of cost, market and manufacturing.

\section{Thermal Management of Power Electronics System in EV}

As mentioned above, automotive manufacturers are adopting high voltage power modules into the powertrain architecture. There is an increasing trend in applying $400 \mathrm{~V}+$ power electronics for BEVs while more energy density batteries become available. In addition to energy efficiency improvements, the application of high voltage power electronics makes electronic system wiring less complex and lighter. Eventually, this will lead to higher miles per charge for EVs despite that there is an ongoing EV range anxiety and low confidence of reliability among end-users. Therefore, validations of various thermal management technologies are prevailing in each specific system design. Viable strategies can be considered and here the potential candidates are mapped out which could be explored to match the cooling demands, as depicted in Fig. 12. Current thermal management and cooling solution pose a growing concern for high voltage power electronics due to the increasing heat losses in wide applications. Therefore, some challenges on such synergetic design processes are also addressed.

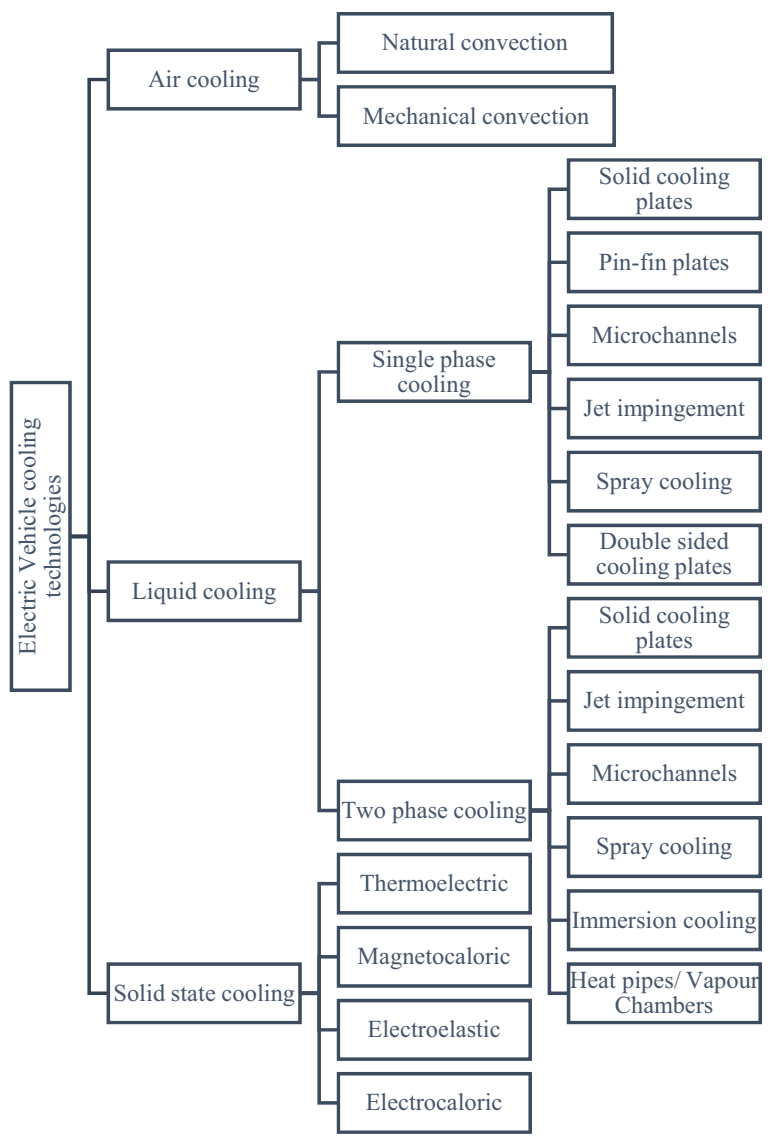

Fig. 12 Potential cooling techniques for high-power electronics in powertrain

After evolving step by step over the past three decades, insulated gate bipolar transistors (IGBTs) and metal-oxide-semiconductor field-effect transistors (MOSFETs) now dominate the power semiconductor market in applications such as motor drives. These two types of semiconductors are structurally different but similar in principle 
of diverting the current flow from gate driver. Working as current and voltage regulating and switching devices, the subsystem contains lot of components such as dies, discrete devices, DC link capacitors, laminated busbar, switching drivers, voltage protectors, sensors for voltage, current and temperature. Nevertheless, both semiconductor power losses are dissipated in the form of heat, which must be transferred away from the switching junction effectively, otherwise the rising temperature will limit the performance and long-term reliability of some key components such as dies, interconnectors and solders. The heat generated from dies is highly dependent on the layouts design. Thermal limit of each component is a key factor that indicates the quality of whole module packaging process.

Mainly, the heat losses can be divided into two categories: (1) conduction losses-voltage drop across the IGBTs or MOSFETs depending on the conducted current; (2) switching losses - on and off stages of the modules depending on the current, duty cycle, switching voltage and switching frequency. In some MOSFETs, only electrons flow during forward conduction without minority carriers. Therefore, switching frequency of MOSFETs is only limited by the applied charges and the capacitances itself. This means it could be applied under higher switching frequency with less parasitic heat losses. On the other hand, IGBTs could achieve higher current density and capability than MOSFETs, and it could achieve much lower on-state voltage decrease. So the balance in trade-offs between switching and conduction losses needs to be carefully evaluated when selecting the proper products to match specific performance requests such as family cars or roadsters in different niche markets.

\subsection{Power Module Cooling Challenges: A Power Density Problem}

The heat transfer path through source to heat sink is usually evaluated by lumped parameter analysis. There are many $1 \mathrm{D}, 2 \mathrm{D}$, pesudo-2D and full 3D thermal resistance

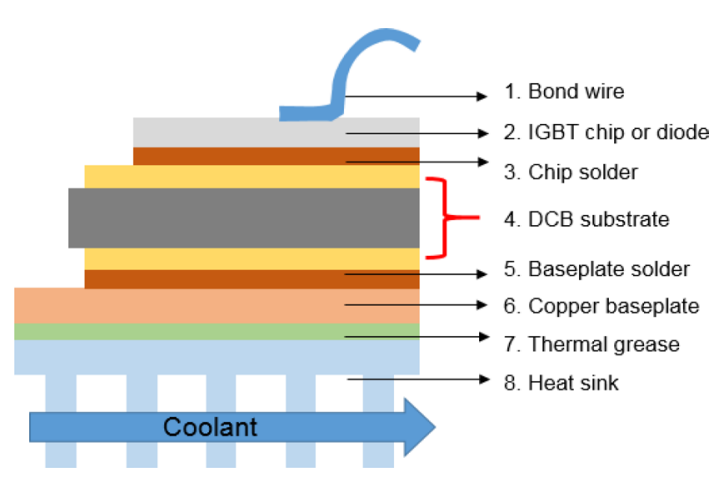

Fig. 13 Conventional air-cooled power module structure models available, following the basic structure as depicted in Fig. 13. Traditionally, the thermal resistance of baseplate from case and heat sink to ambient creates most cause of temperature difference; research focuses on various cooling methods or new materials to enhance the heat transfer in order to minimise the thermal impacts including adopting $\mathrm{SiC}, \mathrm{AlN}, \mathrm{GaN}$ or other advanced wideband gap materials. Although not all performance problems are caused by thermally related issues, the whole packaging lifespan will eventually be reflected thermally in real operations such as wiring lift-offs, solder creeping/climbing, layer delamination and cracks due to rapid and frequent thermal shocks $[68,69]$.

Heat flux in power modules is varied which depended on the duty cycle and real-time switching frequency; it range from below $10 \mathrm{~W} / \mathrm{cm}^{2}$ to $1000 \mathrm{~W} / \mathrm{cm}^{2}$ in microseconds. As shown in Fig. 14, the heat flux curves also closely link to different duty cycles; these variations add more complexity to thermal analysis in design phase. In most designs, the worstcase scenario is usually selected and studied when sizing the thermal management system [70]. In other words, unfortunately, the thermal imbalance problem remains unsolved in most cases. It is suggested here that both thermal load and temperature distribution issues should be comprehensively considered. Localised hotspots around junctions should be tackled with appropriate heat spreading techniques, and the abundant thermal layers like baseplate could be removed or integrated into heat sinks. Higher thermal conductivity materials, such as aluminium nitride (AlN) [71], are being explored in order to replace aluminium oxides $\left(\mathrm{Al}_{2} \mathrm{O}_{3}\right)$ ceramic substrates.

\subsection{Cutting-Edge Power Electronic Cooling Solutions}

The choices of cold source in the automotive are quite different from other sectors. The parasitic heat loss from vehicle will be dissipated into ambient air ultimately even if energy storage systems are involved. Therefore, cooling

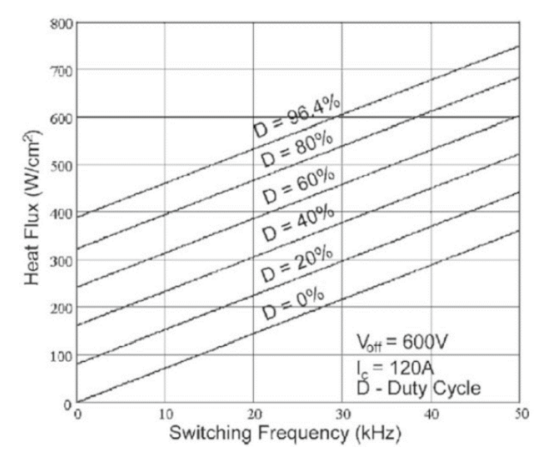

Fig. 14 Example of heat flux versus switching frequency in different duty cycles for a typical IGBT $\left(V_{\text {off }}=600 \mathrm{~V}, I_{\mathrm{c}}=120 \mathrm{~A}\right)[70]$ 


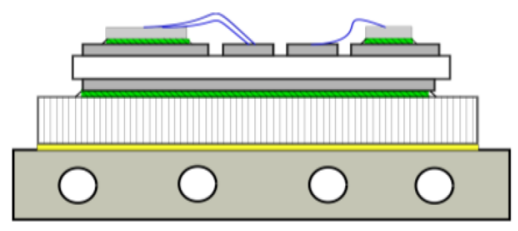

(a)

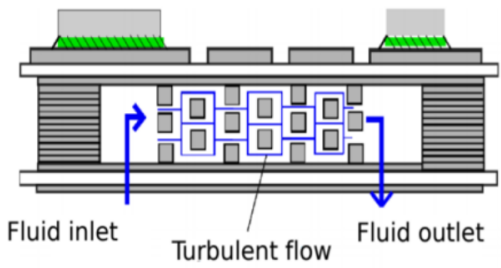

(d)

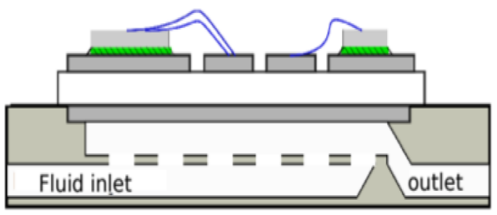

(b)

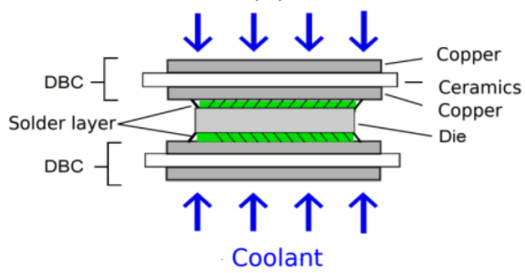

(e)

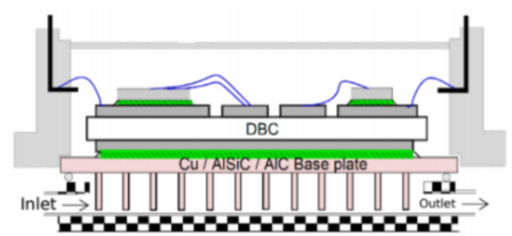

(c)

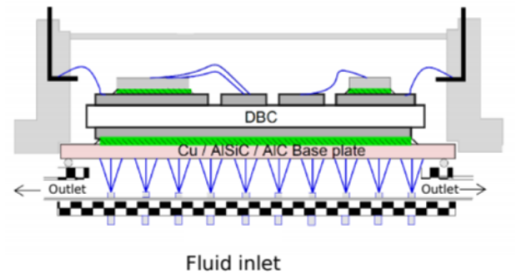

(f)

Fig. 15 Liquid cooling with various configurations: a cooling plates, $\mathbf{b}$ direct substrate liquid cooling, $\mathbf{c}$ pin fins, $\mathbf{d}$ micro-channels, e double-side cooling, f spray/impingement cooling

thorough ventilation is the most economical way to have a system built upon. Such single-phase cooling technologies including air and water-glycol are mostly used in thermal management of power modules as depicted in Fig. 15. With increasing heat dissipation rate, however, it is predicted that conventional air cooling solution fails to meet cooling demand sufficiently, especially when the power dissipation exceeds up to $1500 \mathrm{~W}$ [72]. Micro- and mini-channel liquid cooling solutions were focused over the past decade. It has a major advantage of simplicity of heat sink design due to compactness and lightweight. It can also offer a higher cooling capacity (typically $120 \mathrm{~W} / \mathrm{cm}^{2}$ ) in comparison with that of air cooling (typically $50 \mathrm{~W} / \mathrm{cm}^{2}$ ) [73]. Yin et al. [71] designed a rectangular micro-channel heat sink fabricated directly in the AlN layer of substrate. The simulation results showed that the thermal resistance of the proposed structure was $0.128 \mathrm{~K} / \mathrm{W}$ at a pressure drop of $66.6 \mathrm{kPa}$, which was reduced by $80 \%$ compared with conventional structure. Stevanovic et al. [74] developed an integral micro-channel heat sink for power electronics. An array of sub-millimetre channels was directly fabricated on the back side of the substrate. The junction to fluid thermal resistance for IGBTs was $0.17^{\circ} \mathrm{C} \cdot \mathrm{cm}^{2} / \mathrm{W}$. Vafai et al. [75] proposed a numerical model to analyse two-layered micro-channel heat sink with respect to thermal performance and pressure drop. It was found that the streamwise temperature rise on the base surface and pressure drop were both reduced in comparison with the one-layered heat sink. Naqiuddin et al. [76] reviewed microchannel design for high heat flux applications such as solar cell, fuel cell, heat exchanger and medical system. However, low temperature uniformity caused by flow redistribution, channel clogging erosion and low-term reliability still need to be carefully considered. In particular, heat transfer coefficient of micro-channels strongly depends on the size of channel and fluid flow rate, whereas pumping power inevitably increases with heat transfer rate. In order to decrease the working load of pump, jet impingement becomes an attractive cooling method [77-80]. It is able to generate high flow rate of fluid with lower pump pressure and yield high local heat transfer rate. Jörg et al. [81] developed a direct single impinging jet for cooling of a MOSFET power electronic module. Heat transfer rate could be as high as $12,000 \mathrm{~W} /$ $\mathrm{m}^{2} \cdot \mathrm{K}$. Nonetheless, temperature distribution of the cooled surface is non-uniform because cooling performance rapidly degrades when it is away from the center of the jet region. In order to improve temperature uniformity, array impingement cooling should be paid more attention. Bhunia [82] carried out an experiment about an array impingement cooling system employing 441 nozzles, each with a diameter of $200 \mu \mathrm{m}$. Results indicated that the average heat transfer coefficient was not largely reduced and it was capable of cooling a few square centimetre area to hundred square centimetre area. Gould et al. [83] contrasted thermal performance of cold plat cooling, micro-channel cooling and the array jet impingement cooling of silicon carbide power conversion module for vehicle application. The jet impingement cooling reduces junction to coolant thermal resistance by 2.8 and 1.7 times compared to cooling plate and micro-channel cooler. In general, heat flux levels of around $250 \mathrm{~W} / \mathrm{cm}^{2}$ and $1000 \mathrm{~W} /$ $\mathrm{cm}^{2}$ for water have been reported for single-phase and phase change impingement, respectively [84-87]. Although jet impingement can achieve a very high heat transfer coefficient, the applicability of this strategy is limited by problems of high cost, complex cooling flow redistribution, cooling loop leakage and channel blockage. Therefore, economical but more reliable thermal management device is needed for power module cooling purpose. Phase change cooling strategy becomes more attractive under higher thermal demands. 
Nonneman et al. [88] applied a model-based study on different cooling performance of power modules that integrated phase changing cooling which could match with such power density problem. Hou et al. [89] introduced an open-loop two-phase system for high heat flux electronics experimentally which can dissipate over $380 \mathrm{~W} / \mathrm{cm}^{2}$ while keeping chip temperature at $90{ }^{\circ} \mathrm{C}$.

Vapour chamber/heat pipe, as close-looped phase change cooling components, is a superheat conductive device, and it now represents an appealing option for efficient cooling electric components. Vapour chamber is a vacuum metallic container with wick structure lining the internal walls saturated with working fluid. It utilises cyclic phase change heat transfer process which can absorb much more heat than single-phase heat transfer process. Generally, a vapour chamber effective thermal conductivity is in the range of $1000 \mathrm{~W} / \mathrm{cm}^{2}$ to $50,000 \mathrm{~W} / \mathrm{cm}^{2}$ [71]. Figure 16 illustrates the operational principle of a vapour chamber. In this case, as heat dissipated by IGBT chips and diodes is applied, the working fluid will immediately vaporise to fill the vacuum. Then, vapour releases its latent heat of vaporisation and condenses when it comes into contact with a cooler wall surface. Cyclically, condensed fluid returns to the heat sources due to capillary action in sintered copper wick structure lined inside wall, ready to be vaporised again and repeat next cycle. The capillary force of wick structure enables vapour chamber to overcome gravity and work in any orientation.

The size of vapour chamber is compact and the same as the area of IGBT module. The most common envelope/wick and working fluid combinations are copper/water for electronics cooling. Compared with copper baseplate, vapour chamber has much higher thermal conductivity, better uniform temperature distribution, better durability and lighter weight. Moreover, vapour chamber can be integrated in many heat sinks such as pin fin structure. Li et al. and Wang et al. [90-95] conducted many research on vapour chamber and heat pipe with respect to wick structure and ultra-thin flattened heat pipes. Avenas et al. [96], Chen et al. [97], Qi et al. [98] and Hose [99] developed a power module with vapour chamber heat spread. Ivanova et al. [100] proposed

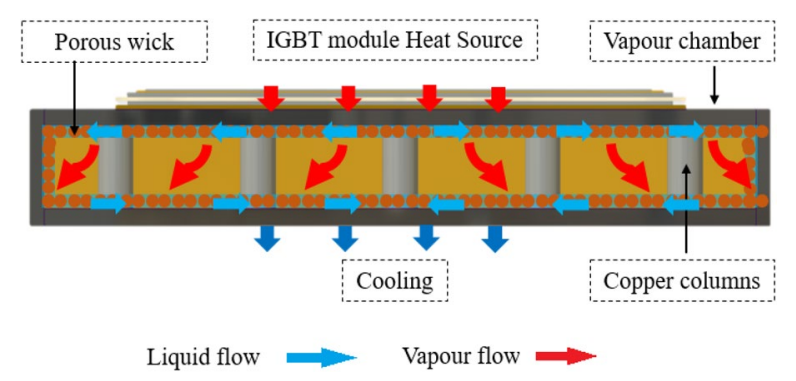

Fig. 16 Illustrative schematic principle of vapour chamber with bonded IGBT substrates a heat pipe directly integrated in DBC for cooling of power semiconductor module packaging. As a result, it can reduce the high heat flux to a lower and manageable level which can be dissipated through traditional cooling solution. Bose et al. [101] experimentally and numerically investigated the thermal performance of a vapour chamber for electronic cooling applications. The maximum temperature reduces by $26 \%$, and the mean deviation in temperature distribution is decreased from $12.5 \%$ to $9 \%$ compared with processor without vapour chamber. Wong et al. [102] designed a vapour chamber with parallel groove and found that it has good thermal performance with low thermal resistance and large thermal limit under different orientations.

\subsection{Trends in Integrating Power Electronics into Electrified Powertrain}

To understand this fast-evolving industry, it is recognised that power electronics research is application driven, not technology driven like other electronics areas. As an example, the EV/HEV segment is driven technologically by $\mathrm{CO}_{2}$ emission reduction targets, higher efficiency requirements or less dependency on the fossil fuel industry. The electrification of passenger vehicles is revolutionising the power electronics industry from market and business perspectives, as well as from technology innovations. With improved power density of electronic modules, it is more sensible to integrate them into the electric machine for energy efficiency improvement.

New semiconductor materials, wideband gap semiconductors, $\mathrm{SiC}$ and $\mathrm{GaN}$, are intrinsically advantageous compared to silicon due to their higher band gaps, higher thermal conductivity, lower conduction losses and higher electron mobility. This gives the possibility to reduce the components size and passive devices since the switching frequency can be increased while having overall less parasitic heat losses which in turn could make the powertrain system more efficient. Wideband gap manufacturers may still have few years before mass production in automotive sector since they are very active and many pioneering prototypes are in development with original equipment manufacturers (OEMs).

In addition, new dies attachment technologies, new mould packages and packing technologies will raise new thermal challenges; such miniaturisation efforts will lead to significant power density increase. For example, new thinner film insulators, new bond-free interconnection method and new substrate material will change the thermal path completely. Without comprehensive understandings of the thermal behaviours of new materials, it is critical for thermal engineering to provide appropriate cooling solutions to the integration efforts. Figure 17 shows a prevailing research development among car manufacturers implying that a common cooling source linking all heat sources needs to be found. 


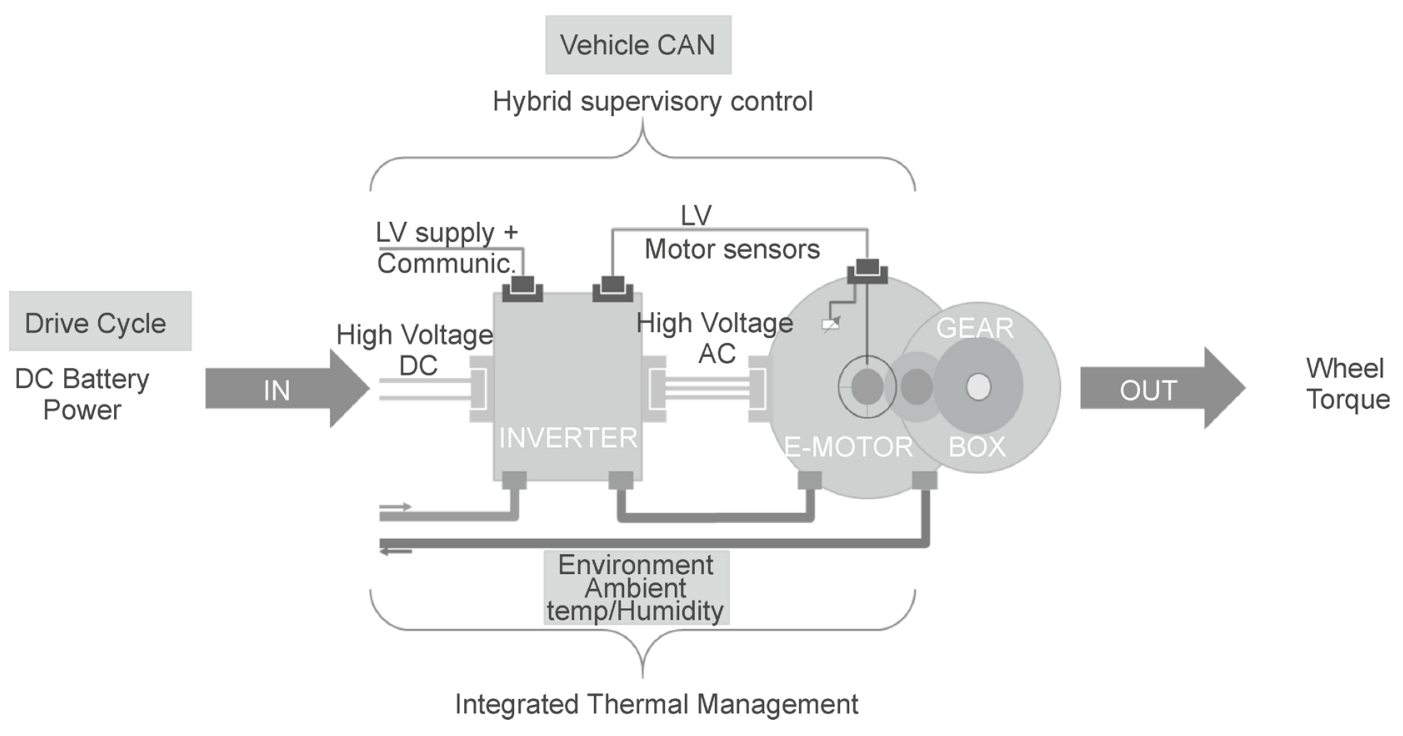

Fig. 17 Illustrative schematic of cooling concept of critical components in powertrain

As configured, the cooling fluid, oil, water-glycol or other advanced heat transfer fluid could be considered to extract the heat losses from inverter (high heat flux), motor (high loss) and gearbox (lubrication). In addition, the fluids could be the same from battery cooling. The overall cooling loops could be simplified with lighter pipes, valves and sensors in the HVAC subsystem. Therefore, it is imperative to find a fluid with wider range of operational condition. Working temperature range in different components varies. Batteries provide high-voltage DC with optimal temperature from 15 to $45^{\circ} \mathrm{C}$; junction temperature in dies needs to be constantly below $150{ }^{\circ} \mathrm{C}$ for products in current generation. Therefore, coolant temperature could reach the boiling point before entering the casing channels and internal structure in which windings temperature is designed to maintain below $180{ }^{\circ} \mathrm{C}$ for continuous operations. When temperature increases over the Curie points, magnetic materials in motor could experience irreversible losses in performance which cannot be repaired by remagnetisation. In some high-speed induction motors, the AC losses could also cause significant temperature increase that leads to performance loss or even hazardous consequences. Currently, many heat transfer fluids, such as mineral oil and dielectric lubricants, could perform at higher flashing points. Without the delicate consideration of gearbox cooling and lubrication, plentiful fluids are available in the market. However, the stringent lubrication requirement imposes another difficulty on the fluid selection and mechanical design process. Usually, the oil temperature should be below $90{ }^{\circ} \mathrm{C}$, while a warm-up may still be needed in some extreme cold weather. The properties of oil or heat transfer fluids, such as viscosity, should be rationally reviewed at wider temperature range.
Last but not least, the choices of integrating power electronics into electric motors are flexible and depend on the specific performance requests. The evolving configuration, from box-to-box to coaxial, could be achieved in smaller volume but with increased power density and output. It is expected that more prototypes of fully integrated units will emerge in the next few years so that power electronic system could be completely embedded into the motor casing and sharing cooling loops become a realistic thermal management approach [103, 104].

\section{Conclusions}

The current advanced techniques of thermal management, which could be applied to facilitate the development of integrated electric machine, have been summarised, and as a conclusion, a mechanic-electric-thermal holistic approach is suggested at early design phase. In addition, a brief introduction of the emerging novel cooling techniques, such as vapour chamber cooling, is presented; meanwhile, the keys to a successful integration can be concluded as:

1. Thermal management for electrified powertrain plays an important role in extending the driving range for EVs, as well as maintaining the optimal working condition of motor and electronics. A synergetic design process is needed to further achieve highly integrated electrified powertrain system.

2. Some advanced cooling technologies offer hopes for the future HVAC system in electrified powertrain. A high- 
efficiency HVAC system is essential for commercial EVs to meet the requirement of thermal comfort and driving range under different climate challenges.

3. Single-phase or two-phase liquid cooling solutions, such as micro-channel heat sink cooling, spray cooling and jet impingement cooling, can provide very high heat transfer coefficients and low thermal resistance. And heat pipes/vapour chamber cooling solutions provide integrated methods to automotive thermal management system. Experiments and simulations provided supportive data on the thermal improvement in power electronic device that could be applied into applications.

Also, vehicular system-level cooling strategy should be considered comprehensively and a holistic approach with economic cost analysis is suggested. In near future, the thermal management control tends to be centralised into centre console as energy control platform while be more interactive with passengers individually. Therefore, the Internet of things, with real-time data processing capacity, could provide more decision-making control strategies to both cabin thermal comforts and powertrain thermal management. Such control strategies will be more intelligent to facilitate such developments and adapt to stringent regulations and climate challenges.

Acknowledgement This project has been supported in the frame of the BIS-Funded Programme 113167 and the Royal Society project 1130182 and European Union project H2020—MSCA—RISE 778104.

\section{Compliance with ethical standards}

Conflict of interest On behalf of all the authors, the corresponding author states that there is no conflict of interest.

Open Access This article is licensed under a Creative Commons Attribution 4.0 International License, which permits use, sharing, adaptation, distribution and reproduction in any medium or format, as long as you give appropriate credit to the original author(s) and the source, provide a link to the Creative Commons licence, and indicate if changes were made. The images or other third party material in this article are included in the article's Creative Commons licence, unless indicated otherwise in a credit line to the material. If material is not included in the article's Creative Commons licence and your intended use is not permitted by statutory regulation or exceeds the permitted use, you will need to obtain permission directly from the copyright holder. To view a copy of this licence, visit http://creativecommons.org/licenses/by/4.0/.

\section{References}

1. Park, S.: A comprehensive thermal management system model for hybrid electric vehicles. University of Michigan (2011)

2. Sean, O., Sarah, N., Andy, S., David, L., Erika, N.: Automotive thermal management technology. International Council on Clean Transportation (2016)
3. Bennion, K., Thornton, M.: Integrated vehicle thermal management for advanced vehicle propulsion technologies. SAE Technical Papers (2010)

4. Bouvy, C., Baltzer, S., Jeck, P., Gißing, J., Lichius, T., Eckstein, L.: Holistic vehicle simulation using modelica-an application on thermal management and operation strategy for electrified vehicles. In: Proceedings of the 9th International MODELICA Conference, pp. 264-270 (2012)

5. Lajunen, A., Yang, Y., Emadi, A.: Recent developments in thermal management of electrified powertrains. IEEE Trans. Veh. Technol. 67(12), 11486-11499 (2018)

6. Zhang, T., Gao, C., Gao, Q., Wang, G., Liu, M., Guo, Y., Xiao, C., Yan, Y.Y.: Status and development of electric vehicle integrated thermal management from BTM to HVAC. Appl. Therm. Eng. 88, 398-409 (2015)

7. Tian, Z., Gan, W., Zhang, X., Gu, B., Yang, L.: Investigation on an integrated thermal management system with battery cooling and motor waste heat recovery for electric vehicle. Appl. Therm. Eng. 136, 16-27 (2018)

8. Neubauer, J., Wood, E.: Thru-life impacts of driver aggression, climate, cabin thermal management, and battery thermal management on battery electric vehicle utility. J. Power Sources 259, 262-275 (2014)

9. Wang, Q., Jiang, B., Li, B., Yan, Y.: A critical review of thermal management models and solutions of lithium-ion batteries for the development of pure electric vehicles. Renew. Sustain. Energy Rev. 64, 106-128 (2016)

10. Tran, D.-D., Vafaeipour, M., El Baghdadi, M., Barrero, R., Van Mierlo, J., Hegazy, O.: Thorough state-of-the-art analysis of electric and hybrid vehicle powertrains: topologies and integrated energy management strategies. Renew. Sustain. Energy Rev. 119, 109596 (2020)

11. Lambert, S.M., Mecrow, B.C., Abebe, R., Vakil, G., Johnson, C.M.: Integrated drives for transport-a review of the enabling thermal management technology. In: 2015 IEEE Vehicle Power and Propulsion Conference (VPPC), pp. 1-6. IEEE (2015)

12. Wei, C., Hofman, T., Ilhan Caarls, E., van Iperen, R.: Integrated energy and thermal management for electrified powertrains. Energies 12, 2058 (2019)

13. Horrein, L., Bouscayrol, A., Cheng, Y., Dumand, C., Colin, G., Chamaillard, Y.: Influence of the heating system on the fuel consumption of a hybrid electric vehicle. Energ. Convers. Manage. 129, 250-261 (2016)

14. Weustenfeld, T.A., Bauer-Kugelmann, W., Menken, J.C., Strasser, K., Köhler, J.: Heat flow rate based thermal management for electric vehicles using a secondary loop heating and cooling system. In: Proceedings of the Vehicle Thermal Management Systems Symposium and Exhibition (VTMS), pp. 10-13 (2015)

15. Hamut, H.S., Dincer, I., Naterer, G.F.: Analysis and optimization of hybrid electric vehicle thermal management systems. J. Power Sources 247, 643-654 (2014)

16. Enthaler, A., Weustenfeld, T., Gauterin, F., Koehler, J.: Thermal management consumption and its effect on remaining range estimation of electric vehicles. In: 2014 International Conference on Connected Vehicles and Expo (ICCVE), pp. 170-177. IEEE (2014)

17. Bayraktar, I.: Computational simulation methods for vehicle thermal management. Appl. Therm. Eng. 36, 325-329 (2012)

18. Qi, Z.: Advances on air conditioning and heat pump system in electric vehicles-a review. Renew. Sustain. Energy Rev. 38, 754-764 (2014)

19. Zhang, Z., Li, W., Zhang, C., Chen, J.: Climate control loads prediction of electric vehicles. Appl. Therm. Eng. 110, 1183-1188 (2017) 
20. Zhang, Z., Wang, J., Feng, X., Chang, L., Chen, Y., Wang, X.: The solutions to electric vehicle air conditioning systems: a review. Renew. Sustain. Energy Rev. 91, 443-463 (2018)

21. Wang, D., Yu, B., Li, W., Shi, J., Chen, J.: Heating performance evaluation of a $\mathrm{CO}_{2}$ heat pump system for an electrical vehicle at cold ambient temperatures. Appl. Therm. Eng. 142, 656-664 (2018)

22. Suzuki, T., Ishii, K.: Air conditioning system for electric vehicle. SAE Technical Paper (1996)

23. Brodie, B.R., Takano, Y., Gocho, M.: Evaporator with integrated ejector for automotive cabin cooling. SAE Technical Paper (2012)

24. Nemesh, M., Martinchick, M., Ibri, S.: Cabin heating and windshield defrosting for extended range electric, pure electric, \& plug-in hybrid vehicles. SAE Int. J. Altern. Powertrains 1, 12-18 (2012)

25. Apfelbeck, R., Barthel, F.: Heating comfort and range perfectly combined-heating systems for vehicles with alternative drive system. Prospects and challenges of biofuel-operated water and air heaters. SAE Technical Paper (2013)

26. Cap, C., Hainzlmaier, C.: Layer heater for electric vehicles. ATZ Worldwide 115(6), 16-19 (2013)

27. Shin, Y.H., Ahn, S.K., Kim, S.C.: Performance characteristics of ptc elements for an electric vehicle heating system. Energies 9(10), 813 (2016)

28. Bauml, T., Dvorak, D., Frohner, A., Simic, D.: Simulation and measurement of an energy efficient infrared radiation heating of a full electric vehicle. In: 2014 IEEE Vehicle Power and Propulsion Conference (VPPC), pp 1-6 (2014)

29. Clodic, D ZE., Mortada, S.: Impacts of heating and cooling on electrified vehicles. In: Proceedings of the 4th European Workshop-MAC and Vehicle Thermal Systems (2011)

30. Peng, Q., Du, Q.: Progress in heat pump air conditioning systems for electric vehicles-a review. Energies 9(4), 240 (2016)

31. Zhang, Z., Wang, D., Zhang, C., Chen, J.: Electric vehicle range extension strategies based on improved AC system in cold climate-a review. Int. J. Refrig 88, 141-150 (2018)

32. Hosoz, M., Direk, M.: Performance evaluation of an integrated automotive air conditioning and heat pump system. Energy Convers. Manag. 47(5), 545-559 (2006)

33. Kim, K.Y., Kim, S.C., Kim, M.S.: Experimental studies on the heating performance of the PTC heater and heat pump combined system in fuel cells and electric vehicles. Int. J. Automot. Technol. 13(6), 971-977 (2012)

34. Li, H.-J., Zhou, G.-H., Li, A.-G., Li, X.-G., Li, Y.-N., Chen, J.: Heat pump air conditioning system for pure electric vehicle at ultra-low temperature. Therm. Sci. 18, 1667-1672 (2014)

35. Zhou, G.-H., Li, H.-J., Liu, L., Zhao, D.-K., Wei, P.-P., Chen, T.: Numerical approach to a low pressure gas-injection scroll compressor. Therm. Sci. 19, 1383-1388 (2015)

36. Qian, C., Gu, B., Tian, Z., Ma, L., Yang, L.: Performance analysis of dual source heat pump in electric vehicles. Appl. Energy 50, 569-574 (2016)

37. Shahidinejad, S., Bibeau, E., Filizadeh, S.: Design and simulation of a thermal management system for plug-in electric vehicles in cold climates. SAE Technical Paper (2012)

38. Li, Z., Jiang, Y.: The schemes of air conditioning system and cooling system in electric vehicle. Shanghai Auto (2017)

39. Gómez, J.R., Garcia, R.F., Catoira, A.D.M., Gómez, M.R.: Magnetocaloric effect: a review of the thermodynamic cycles in magnetic refrigeration. Renew. Sustain. Energy Rev. 17, 74-82 (2013)

40. Muller, C.: New reversible air-conditioning magnetocaloric system, environmentally friendly and highly energy efficient. SAE Technical Papers (2009)
41. Vasile, C., Muller, C.: Innovative design of a magnetocaloric system. Int. J. Refrig. 29(8), 1318-1326 (2006)

42. Alaoui, C., Salameh, Z.M.: A novel thermal management for electric and hybrid vehicles. IEEE Trans. Veh. Technol. 54(2), 468-476 (2005)

43. Evspecifications. https://www.evspecifications.com/en/model/ e1d178

44. Pellegrino, G., Vagati, A., Boazzo, B., et al.: Comparison of induction and pm synchronous motor drives for EV application including design examples. IEEE. Trans. Ind. Appl. 48(6), 2322-2332 (2012)

45. Jabbour, N., Mademlis, C.: Online parameters estimation and autotuning of a discrete-time model predictive speed controller for induction motor drives. IEEE. Trans. Power. Electr. 34(2), 1548-1559 (2019)

46. Ouhrouche, M., Errouissi, R., Trzynadlowski, A.: A novel predictive direct torque controller for induction motor drives. IEEE. Trans. Ind. Electron. 63(8), 5221-5230 (2016)

47. Cavazzuti, M., Gaspari, G., Pasquale, S.: Thermal management of a formula e electric motor: analysis and optimization. Appl. Therm. Eng. 157, 113733 (2019)

48. Chiu, H., Jang, J., Yan, W.: Thermal performance analysis of a $30 \mathrm{~kW}$ switched reluctance motor. Int. J. Heat. Mass. Transf. 114, 145-154 (2017)

49. Saidur, R.: A review on electrical motors energy use and energy savings. Renew. Sust. Energy Rev. 14(3), 877-898 (2010)

50. Staton, D., Popescu, M., Hawkins, D.: Influence of different end region cooling arrangements on end-winding heat transfer coefficients in electrical machines. In: Paper Presented at the IEEE Energy Conversion Congress and Exposition, Atlanta, USA (2010)

51. Li, C., St, C., Li, J.: Heat dissipation evaluation and optimization of air cooling induction motor used for mini electric vehicle. In: Paper Presented at the 20th International Conference on Electrical Machines and Systems (ICEMS), Sydney, Australia (2017)

52. Ahmed, F., Ghosh, E., Kar, N.: Transient thermal analysis of a copper rotor induction motor using a lumped parameter temperature network model. In: Paper Presented at the IEEE Transportation Electrification Conference and Expo (ITEC), Dearborn, USA (2016)

53. Moon, S., Jung, Y., Kim, K.: Numerical investigation on thermalflow characteristics of a totally enclosed fan cooled induction motor. In: Paper Presented at the XXII International Conference on Electrical Machines (ICEM), Lausanne, Switzerland (2016)

54. Kim, C., Lee, K., Yook, S.: Effect of air-gap fans on cooling of windings in a large-capacity, high-speed induction motor. Appl. Therm. Eng. 100, 658-667 (2016)

55. Song, L., Li, Z., Gao, Q.: 3D thermal analysis of water cooling induction motor used for HEV. In: Paper Presented at the 2008 International Conference on Electrical Machines and Systems, Wuhan, China (2008)

56. Ranjan, R., Tangudu, J.: Thermal design of high power-density additively- manufactured induction motors. In: Paper Presented at the IEEE Energy Conversion Congress and Exposition (ECCE), Pittsburgh, USA (2014)

57. Herbst, J., Hahne, J., Jordan, H.: Challenges in the design of a $100 \mathrm{kw}$ induction motor for a phev application. In: Paper Presented at the IEEE Vehicle Power and Propulsion Conference, Dearborn, USA (2009)

58. Assaad, B., Mikati, K., Tran, T.: Experimental study of oil cooled induction motor for hybrid and electric vehicles. In: Paper Presented at the XIII International Conference on Electrical Machines (ICEM), Alexandroupoli, Greece (2018)

59. Fawzal, A., Cirstea, R., Gyftakis, K.: The fan design impact on the rotor cooling of axial flux permanent magnet machines. In: 
Paper Presented at the XXII International Conference on Electrical Machines (ICEM), Lausanne, Switzerland (2016)

60. Lee, K., Cha, H., Kim, Y.: Development of an interior permanent magnet motor through rotor cooling for electric vehicles. Appl. Therm. Eng. 95, 348-356 (2016)

61. Rocca, A., Arumugam, P., Pickering, S.: Thermal management of a high speed permanent magnet machine for an aeroengine. In: Paper Presented at the XXII International Conference on Electrical Machines (ICEM), Lausanne, Switzerland (2016)

62. Li, Y., Fan, T., Wen, X.: Experimental investigation on heat transfer of directly-oil-cooled permanent magnet motor. In: Paper Presented at the 19th International Conference on Electrical Machines and Systems (ICEMS), Chiba, Japan (2016)

63. Polikarpova, M., Ponomarev, P., Lindh, P.: Hybrid cooling method of axial-flux permanent-magnet machines for vehicle applications. IEEE. Trans. Ind. Electron. 62(12), 7382-7390 (2015)

64. Fasquelle, A., Laloy, D.: Water cold plates cooling in a permanent magnet synchronous motor. IEEE IEEE. Trans. Ind. Appl. 53(5), 4406-4413 (2017)

65. Wang, S., Li, Y., Li, Y., Wang, J., Xiao, X., Guo, W.: Transient cooling effect analyses for a permanent-magnet synchronous motor with phase-change-material packaging. Appl. Therm. Eng. 109, 251-260 (2016)

66. Zhang, X., Wang, H., Zhang, G.: Temperature characteristics in the stator model of a permanent magnet motor by water-cooling and evaporative cooling. In: Paper Presented at International Conference on Electrical Machines and Systems, Nanjing, China (2005)

67. Wang, J., Li, Y., Wang, S.: Experimental investigation of the thermal control effects of phase change material based packaging strategy for on-board permanent magnet synchronous motors. Energy Convers. Manag. 123, 232-242 (2016)

68. Randoll, R., Wondrak, W., Schletz, A.: Lifetime and manufacturability of integrated power electronics. Microelectron. Reliab. 64, 513-518 (2016)

69. Furukawa, Y., Yamauchi S.: 5-Technologies of a cooling device for power semiconductor. In: Woodhead Publishing Series in Electronic and Optical Materials, Wide Bandgap Power Semiconductor Packaging, Woodhead Publishing, pp. 111-126 (2018)

70. Mertens, R., Chow, L., Sundaram, K.B., Cregger, R.B., Rini, D.P., Turek, L., Saarloos, B.: Spray cooling of IGBT devices. ASME. J. Electron. Packag. 129(3), 316-323 (2017)

71. Yin, S., Tseng, K.J., Zhao J.: Design of AlN-based microchannel heat sink in direct bond copper for power electronics packaging. Appl. Therm. Eng. 52(1), 120-129 (2013)

72. Kandlikar, S.G., Hayner, C.N.: Liquid cooled cold plates for industrial high-power electronic devices - thermal design and manufacturing considerations. Heat Transf. Eng. 30(12), 918930 (2019)

73. Wang, P., McCluskey, P., Bar-Cohen, A.: Two-phase liquid cooling for thermal management of IGBT power electronic module. J Electron Packag. 135(2), 021001 (2013)

74. Stevanovic, L.D., Beaupre, R.A. Gowda, A.V., et al.: Integral micro-channel liquid cooling for power electronics. In: Paper Presented at the Twenty-Fifth Annual IEEE Applied Power Electronic Conference and Exposition (APEC), Palm Spring, USA (2010)

75. Vafai, K., Zhu, L.: Analysis of two-layered micro-channel heat sink concept in electronic cooling. Int. J. Heat Mass Transf. 42(12), 2287-2297 (1999)

76. Naqiuddin, N., Saw, M., Yew, F., et al.: Overview of microchannel design for high heat flux application. Renew. Sust. Energy Rev. 82, 901-914 (2018)

77. Cassou, A., Tounsi, Fradin, J.: Using compact thermal modelling for the investigation of a cooling system dysfunction applied to a power module with double sided cooling. In: Paper Presented at the 26th International Conference Mixed Design of Integrated Circuits and Systems, Rzeszów, Poland (2019)

78. Bostanci, H., Van, B., Saarloos, A., et al.: Spray cooling of power electronics using high temperature coolant and enhanced surface. In: Paper Presented at the IEEE Vehicle Power and Propulsion Conference, Dearborn (2009)

79. Shailesh, J., Ercan, M.: Two-phase jet impingement cooling for high heat flux wide band-gap devices using multi-scale porous surfaces. Appl. Therm. Eng. 110, 10-17 (2017)

80. Pritish, R., Srinath, V., Khai, N.: Impingement-based high performance cooling configurations for automotive power converters. Int. J. Heat Mass Transf. 55(4), 834-847 (2012)

81. Jörg, S., Taraborrelli, G., Sarriegui, R., et al.: Direct single impinging jet cooling of a MOSFET power electronic module. IEEE Trans. Power Electr. 33(5), 4224-4237 (2017)

82. Bhunia, A., Chen, C.: On the scalability of liquid microjet array impingement cooling for large area systems. J. Heat Transf. 133(6), 064501 (2011)

83. Gould, S., Cai, Q., Neft, A.: Liquid jet impingement cooling of a silicon carbide power conversion module for vehicle applications. IEEE Trans. Power Electr. 30(6), 2975-2984 (2015)

84. Oliphant, K., Webb, B., McQuay, M.: An experimental comparison of liquid jet array and spray impingement cooling in the non-boiling regime. Exp. Therm. Fluid Sci. 18(1), 1-10 (1998)

85. Fabbri, M., Jiang, S., Dhir, V.: Experimental investigation of single-phase micro jets impingement cooling for electronic applications. In: Paper Presented at the HT2003 ASME Summer Heat Transfer Conference, Las Vegas, USA (2003)

86. Bhunia, A., Cai, Q., Chen. C.: Liquid impingement and phase change for high power density electronic cooling. In: Paper Presented at the 41st AIAA Aerospace Sciences Meeting and Exhibit, Reno, NV (2003)

87. Ditri, J., Hahn, R., Cadotte, M., et al.: Embedded cooling of high heat flux electronics utilizing distributed microfluidic impingement jets. In: Paper Presented at the International Technical Conference and Exhibition on Packaging and Integration of Electronic and Photonic Microsystems, San Francisco, USA (2015)

88. Nonneman, J., T'Jollyn, I., Clarie, N., et al.: Model-based comparison of thermo-hydraulic performance of various cooling methods for power electronics of electric vehicles. In: Paper Presented at the 17th IEEE Intersociety Conference on Thermal and Thermomechanical Phenomena in Electronic Systems (ITherm), San Diego, USA (2018)

89. Hou, F., Wang, W., Zhang, H., Chen, C., Chen, C., Lin, T., Cao, L., Zhang, G.Q., Ferreira, J.A.: Experimental evaluation of a compact two-phase cooling system for high heat flux electronic packages. Appl. Therm. Eng. 163, 114338 (2019)

90. Li, Y., Li, Z., Chen, C., et al.: Thermal responses of heat pipes with different wick structures under variable centrifugal accelerations. Appl. Therm. Eng. 96, 352-363 (2016)

91. Li, Y., Zhou, W., He, J., et al.: Thermal performance of ultra-thin flattened heat pipes with composite wick structure. Appl. Therm. Eng. 102, 487-499 (2016)

92. Li, Y., Li, Z., Zhou, W., et al.: Experimental investigation of vapor chambers with different wick structures at various parameters. Exp. Therm. Fluid Sci. 77, 132-143 (2016)

93. Li, Y., Chen, S., He, B., et al.: Effects of vacuuming process parameters on the thermal performance of composite heat pipes. Appl. Therm. Eng. 99, 32-41 (2016)

94. Wang, X., Zheng, H.C., Si, M.Q., et al.: Experimental investigation of the influence of surfactant on the heat transfer performance of pulsating heat pipe. Int. J. Heat Mass Transf. 83, 586-590 (2015) 
95. Hua, C., Wang, X., Gao, X., et al.: Experimental research on the start-up characteristics and heat transfer performance of pulsating heat pipes with rectangular channels. Appl. Therm. Eng. 126, 1058-1062 (2017)

96. Avenas, Y., Gillot, C., Bricard, A., et al.: On the use of flat heat pipes as thermal spreaders in power electronics cooling. In: Paper Presented at the 33rd Annual IEEE Power Electronics Specialists Conference. Cairns, Qld, Australia (2002)

97. Chen, Y., Yan Y., Li, B., et al.: Thermal characterization analysis of IGBT power module integrated with a vapour chamber and pin-fin heat sink. In: Paper Presented at the International Exhibition and Conference for Power Electronics, Intelligent Motion, Renewable Energy and Energy Management (2017)

98. Qi, F., Wang, Y., Bob-Manuel, C., et al.: Advanced cooling solutions of high power automotive module. In: Paper Presented at the International Exhibition and Conference for Power Electronics, Intelligent Motion, Renewable Energy and Energy Management (2017)

99. Hose, L., Ibitayo, D., et al.: Integrated vapor chamber heat spreader for power module applications. In: Paper Presented at the International Technical Conference and Exhibition on
Packaging and Integration of Electronic and Photonic Microsystems. San Francisco, California, USA (2017)

100. Ivanova, M., Avenas, Y., Schaeffer, C., et al.: Heat pipe integrated in direct bonded copper (dbc) technology for cooling of power electronics packaging. IEEE Trans. Power Electr. 21(6), 1541-1547 (2006)

101. Bose, R., Ahammed, N., Asirvatham, L.: Thermal performance of a vapor chamber for electronic cooling applications. J. Mech. Sci. Technol. 31(4), 1995-2003 (2017)

102. Wong, S., Hsieh, K., Wu, J., et al.: A novel vapor chamber and its performance. Int. J. Heat Mass Transf. 53(11-12), 2377-2384 (2010)

103. López, I., Ibarra, E., Matallana, A., et al.: Next generation electric drives for HEV/EV propulsion systems: technology, trends and challenges. Renew. Sustain Energy Rev. 114, 0321-0364 (2019)

104. Iradukunda, A., Huitink, D., Luo, F.: A review of advanced thermal management solutions and the implications for integration in high-voltage packages. IEEE J. Em Sel. Top. 8(1), 256-271 (2020) 